\title{
Clinical Pharmacist Approach towards Effectiveness of Pulmonary Rehabilitation of the Patient with COPD: A Randomized Controlled Study
}

\author{
Mahantha Vastrad, Shashikala Wali, Madiwalayya Shivakantayya Ganachari, Ashish Singh Parihar, \\ Ramesh Bhandari
}

Department of Pharmacy Practice, KLE College of Pharmacy, KLE Academy for Higher Education and Research (KAHER),

Belagavi, Karnataka, INDIA.

\begin{abstract}
Background: COPD is characterized by chronic obstruction of lung airflow that interferes with normal breathing and is not fully reversible. Pulmonary rehabilitation is widely accepted as a best result outcome treatment for COPD patients. Clinical pharmacist play a very important role in patient prescription analysis, promoting the Quality of life, patient education, in developing the drug regimen, sensitivity and allergic condition of the patient to the drugs, finding out any ADRs. Objectives: To compare and assess the impact of pharmacist approach on Health related quality of Life of COPD patients undergoing pulmonary rehabilitation at two different time point. Results: Total 112 patients were screened as per study criteria, 70 were recruited and randomized into control and intervention groups of 35 each, respectively. Compared to baseline QOL score, it was improved at the follow-up in intervention group. Out of 35 subjects 33 subjects has shown good and very good QOL $(94.28 \%)$. All the domains of QOL were improved compared to control group at the follow-up. Highest improved domain was physical health domain among all (difference 25.83) and lowest was socio-economic domain (difference 12.14) Mean total score of quality of life at follow-up has the significant difference $18.1(p<0.0001)$. Conclusion: This study elaborated that quality of life of patients with COPD undergoing pulmonary rehabilitation was improved after the clinical pharmacists approach when compared to only standard treatment (control group).
\end{abstract}

Key words: COPD, Pulmonary rehabilitation, Collaborative approach, Pharmacist's intervention, Pharmaceutical care, Quality of life.

\section{INTRODUCTION}

The Global Initiative for Chronic Obstructive Lung Disease (GOLD) has suggested that the Pulmonary rehabilitation as the standard treatment for patients with moderate to severe chronic obstructive pulmonary diseases (COPD) $\cdot^{1-3}$ It includes individualized therapy based on patient's symptoms and traits, confining the diagnosis, exercise training, psychological support and health education. These above mentioned are all much necessary to the COPD patients but it is observed that the effectiveness of the pulmonary rehabilitation is enhanced with the approach of pharmacists. ${ }^{3}$
Clinical pharmacists are the licensed healthcare providers and play a very important role in patient evaluation, prescription analysis, promoting the Quality of life and medication adherence, patient education, in developing the drug regimen, sensitivity and allergic condition of the patient to the drugs, finding out any adverse drug reactions (ADRs) and also play a vital role in smoking cessations by educating them. ${ }^{4-6}$ Quality of life is unbalanced in COPD patients and it worsens the disease condition by which socio-economic status reduces leading to poor quality of life (QOL) of the patients. ${ }^{6-8}$ The pharmacists
Submission Date: 25-06-2020; Revision Date: 02-12-2020; Accepted Date: 08-02-2021

DOI: 10.5530/ijper.55.1s.65 Correspondence: Mrs. Shashikala C Wali Assistant Professor, Department of Pharmacy Practice, KLE College of Pharmacy, KLE Academy for Higher Education and Research (KAHER), Belagavi-590010, Karnataka, INDIA.

Phone no: +919902944602 Email id: shashiwali90@ gmail.com

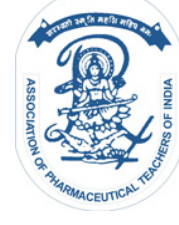

www.ijper.org 
approach in pulmonary rehabilitation for COPD patients can be beneficial with patient education with respective medications, dosage and also increase the health related quality of life of the patients. So this is often the key to remove the barriers occurring within the pulmonary rehabilitation and improve the health benefits of the patients. Therefore, knowing and getting the both negative and positive factors influencing pharmacist's intension to increase benefits of COPD patients in pulmonary rehabilitation can identify where efforts to improve utilization would be best applied. ${ }^{9}$

In India, very few studies have been carried out with pharmacist approach for COPD patients. ${ }^{10,11}$ Moreover, health management and care in India is chiefly guided by physicians with optimal support from other healthcare professionals. ${ }^{5}$ Therefore, we conducted this study in a tertiary care hospital to assess the effectiveness of pharmacist approach on health related quality of life for COPD patients who are undergoing pulmonary rehabilitation with intervention of clinical pharmacist.

\section{MATERIALS AND METHODS}

\section{Ethical clearance}

The study protocol was approved and by Ethics Committee (KLE/COP/450/2019-20), KLE Dr. Prabhakar Kore Charitable Hospital and Medical Research Centre. This was a randomized controlled study.

\section{Study design and Setting}

This randomized controlled study was carried out in the inpatient Department of General Medicine and Respiratory department in a tertiary care hospital in North Karnataka.

\section{Inclusion criteria}

- A voluntarily given, written, signed and dated informed consent from subject and/or legally acceptable representative.

- Patients diagnosed with COPD and undergoing Pulmonary rehabilitation

- Patients of either age and gender (>18 years)

\section{Exclusion criteria}

- Patients having more than 2 exacerbations or any serious condition in the past one year.

- Patients having unbalanced cognitive function.

- Cancer and HIV patients.

- Patients currently or planning to be pregnant in next 6 months.

- Patients planning vacation in next 6 months

\section{Screening and recruitment of patients}

Screening was conducted according to eligibility criteria of the study. Subjects or witness or both were provided and informed in detail about the study. Both were informed about the procedure of research work and right to take back from the study at any moment.

Participants were recruited from the Respiratory Department and Department of General Medicine. The clinical pharmacist provided information about the study to eligible subjects through patient information sheet and patient consent form and their consent had been taken who were willing to participate. The recruited patients were randomized into one of the 2 groups (Intervention or Control group). Subjects who met exclusion criteria were omit from the study and documented.

\section{Outcome measures}

Quality of life of recruited subjects using WHOQOL (Bref) as a measuring tool. It consist 24 questions those are organized into 4 domains: Physical health 7 questions), Psychological health (6 questions), Social relationship (3 questions) and environmental health (8 questions). There are additional 2 questions, which are indicated for overall QOL and health status. Each item or question is derived from five options, that represent the score of particular item or question ranging from 1-5 (5 point scale). In this, two transformation methods are available. First one is to convert domain raw score ranging between 4-20. Second is to convert domain raw score ranging between $0-100$. In present study, $0-100$ transformation scale is considered. The mean score of each domain has transformed to 0-100 scale, higher score represented the improved quality of life.

\section{Statistical analysis}

Chi-square test, Mann-Whitney U test.

\section{Study procedure (Schematic diagram)}

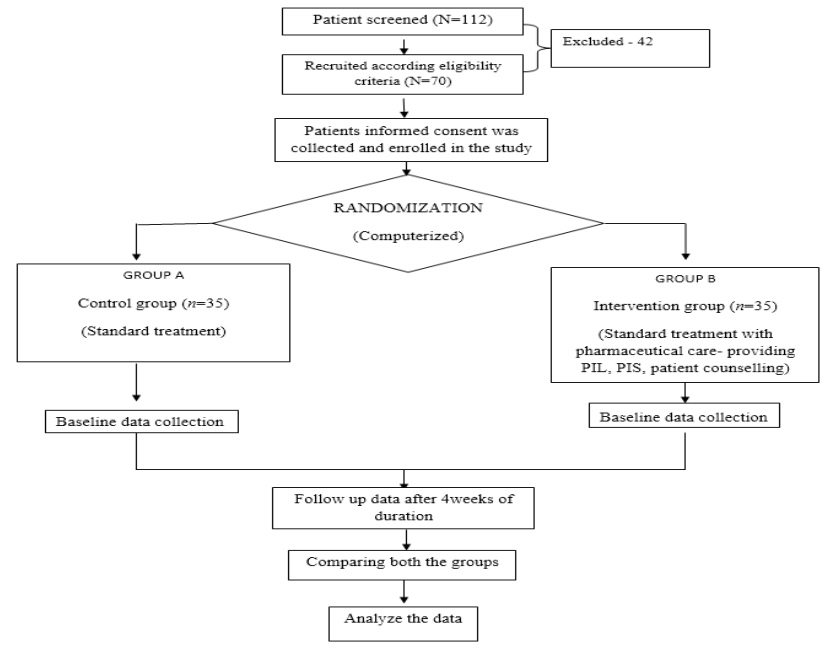




\section{RESULTS}

The patients have been recruited in the study through study criteria. There were total 112 patients in the study. Of them $70(62.5 \%)$ patients were recruited as per the eligibility criteria. Remaining 42(37.5\%) patients were excluded from the study due to fall under exclusion criteria. Among the 42 excluded patients, 2 (5\%) patients were having serious conditions since a year and having serious co-morbid conditions. $31(73.8 \%)$ patients were not willing to participate in the study. $7(16.6 \%)$ patients were planned for vacations and move to other places from the study site and lastly $2(5 \%)$ patients were planning to be pregnant which was included in the exclusion criteria. Patient's demographic details were obtained in the data collection form including age, gender, occupation of the patient, diagnosis, occupation of the patient, qualification, socio-economic status, habits of the patient and their locality.

Total mean QOL score includes transformation score of all four domains. Quality of life cannot be measured or assessed only by any single term. It includes all physical health, mental health, social well-being and environmental health condition. Lack of anyone domain can cause for poor quality of life. So it's important to manage all the conditions in life. As quality of life increases disease management can be improved. It is said that not only medical treatment with medications and exercise can improve the condition unless there is good quality of life. So both should be given equal importance to have a best disease management for COPD patient.

In present study, the mean total score of quality of life of the recruited participants at baseline had much no difference in both control and intervention group (Difference is 1.28). But mean total score of quality of life at follow-up has the significant difference (18.1) as shown in Table 1. It concluded that, at follow-up intervention group has increase of quality of life after the intervention. Study has shown the positive outcome after the intervention.
Mean total score of Quality of life was compared between the two groups by Mann Whitney $U$ test and it was found that it was very highly statistical and clinical significant difference between the baseline and follow-up $(p<0.0001)$.

The physical health domain involves mobility, energy and fatigue, discomfort and pain, daily living activities, rest and sleep. The seven questions of this domain are according to above mentioned terms. These are considered to measure the quality of life of an individual. It is always good to have the better physical health as it is responsible for performing the daily living activities. This matter more in COPD patients because they suffer with cough and breathlessness. As the physical health of a patient improves; symptoms are reduced and a part of quality of life is increased.

In present study, it is found that mean score of physical health domain of recruited patients at baseline is almost similar in both control group and interventional group (difference is 1.14). Mean score of physical health domain at follow-up has shown great difference comparing control and intervention group (difference is 25.83) as depicted in Table 2. Mean score value is high in intervention group as it includes the collaborative approach of healthcare professionals.

In the comparison of control group and intervention group with mean score of physical health domain by Mann Whitney $\mathrm{U}$ test found that there was very high statistical and clinical significance difference between the two groups $(\phi<0.0001)$.

The Psychological health domain is concerned about the self-esteem, depression, anxiety, memory and concentration, negative feelings, appearance and bodily image. This domain included 6 items concerned about mentioned terms. Patient mental health plays important role in the quality of life and is also main reason for disease condition of the patient. Acceptance of illness is another important factor in the psychological health on which many research have been conducted and concluded that it is easier to manage the treatment of disease by accepting the illness by patients leading to the

\begin{tabular}{|c|c|c|c|c|c|c|c|c|}
\hline Variable & Group & N & Mean & SD & $\begin{array}{l}\text { Mean } \\
\text { Rank }\end{array}$ & U-Value & Z-Value & $P$-Value \\
\hline \multirow{2}{*}{$\begin{array}{c}\text { Mean QOL } \\
\text { Baseline }\end{array}$} & Intervention & 35 & 45.85 & 4.27 & 38.76 & \multirow[t]{2}{*}{498.50} & \multirow[t]{2}{*}{-1.345} & \multirow[t]{2}{*}{0.179} \\
\hline & Control & 35 & 44.57 & 5.35 & 32.24 & & & \\
\hline \multirow{2}{*}{$\begin{array}{c}\text { Mean QOL } \\
\text { Follow-up }\end{array}$} & Intervention & 35 & 64.10 & 8.91 & 51.27 & \multirow[t]{2}{*}{60.50} & \multirow[t]{2}{*}{-6.492} & \multirow[t]{2}{*}{$0.0001^{* * *}$} \\
\hline & Control & 35 & 46.05 & 5.00 & 19.73 & & & \\
\hline
\end{tabular}

$p<0.05 *, p<0.01 * *, p<0.0001 * * *$ 
strong and positive mental health of the patient. The psychological health findings can be fixed by healthcare professionals while treating the patients.

In this study, the mean score of psychological health domain of enrolled patients at baseline is not having much difference in control and intervention group. The mean difference was found to be 1.95 but whereas the mean score psychological health domain at follow-up had a great difference that is 17.34 which is shown in Table 3. The mean score has increased after the intervention in the study. This is because of clinical approach by the healthcare professionals.

Psychological health domain was compared between the two groups by Mann Whitney $U$ test and it was found that there was very highly statistical and clinical significant difference between the follow-up and baseline $(p<0.0001)$.

The Social-relationship domain involves personal relationships, sexual activity and social support. This domain included 3 questions about above mentioned terms. Social-relationship is important for the COPD patients because it can improve the health status and disease management and also reduces the hospitalizations. It supports on mental illness of the patients, loneliness and self-management and increase the quality of life. COPD patients who lack with social support may hesitate to care for the fear of negative thoughts and judgment about the disease. So it is very important for patients to know about the socialrelationships. And it is responsible of healthcare professionals to educate patients about the same.

In present study, the mean score of social-relationship domain of recruited patients at baseline have no much difference in both intervention and control group (Difference is 1.1) as shown in Table 4. But mean score of same domain at follow-up has significant difference (Difference is 12.14). Mean score of the domain has increased after the intervention by health care professionals. Patient education plays the very important

\begin{tabular}{|c|c|c|c|c|c|c|c|c|}
\hline Variable & Group & $\mathbf{N}$ & Mean & SD & $\begin{array}{l}\text { Mean } \\
\text { Rank }\end{array}$ & U-Value & Z-Value & $P$-Value \\
\hline \multirow{2}{*}{$\begin{array}{l}\text { Physical Domain } \\
\text { at Baseline }\end{array}$} & Intervention & 35 & 37.94 & 6.07 & 36.76 & \multirow[t]{2}{*}{568.500} & \multirow[t]{2}{*}{-.541} & \multirow[t]{2}{*}{0.588} \\
\hline & Control & 35 & 36.80 & 7.85 & 34.24 & & & \\
\hline \multirow{2}{*}{$\begin{array}{l}\text { Physical Domain } \\
\text { at Follow-up }\end{array}$} & Intervention & 35 & 64.85 & 12.72 & 51.36 & \multirow[t]{2}{*}{57.500} & \multirow[t]{2}{*}{-6.600} & \multirow[t]{2}{*}{$0.0001^{* * *}$} \\
\hline & Control & 35 & 39.02 & 5.89 & 19.64 & & & \\
\hline
\end{tabular}

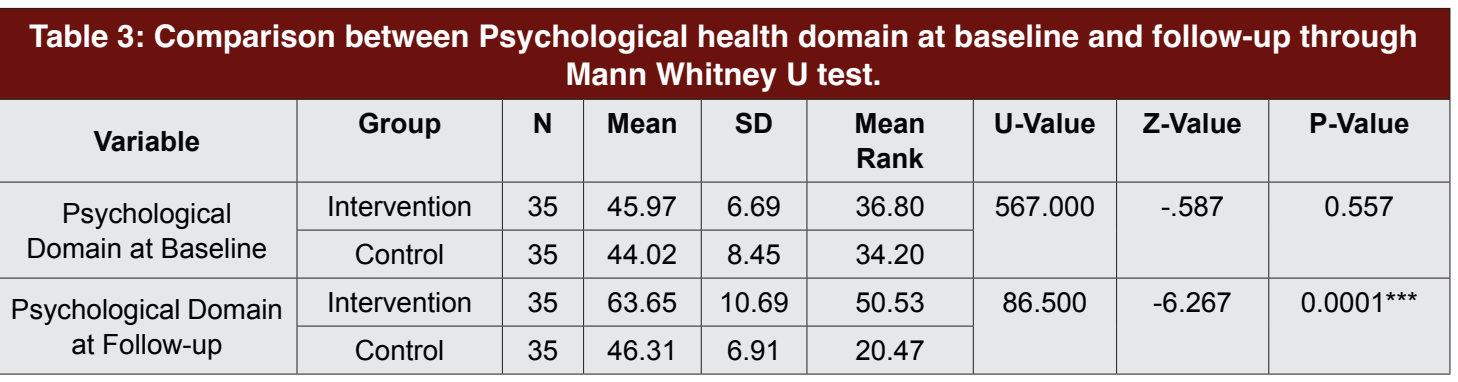

Table 4: Comparison between Social relationship domain at baseline and follow-up through Mann Whitney U test.

\begin{tabular}{|c|c|c|c|c|c|c|c|c|}
\hline Variable & Group & N & Mean & SD & $\begin{array}{c}\text { Mean } \\
\text { Rank }\end{array}$ & U-Value & Z-Value & $P$-Value \\
\hline $\begin{array}{c}\text { Socioeconomic } \\
\text { Domain at } \\
\text { Baseline }\end{array}$ & Intervention & 35 & 55.60 & 10.41 & 34.66 & 583.000 & -.365 & 0.715 \\
\cline { 2 - 8 } & Control & 35 & 54.57 & 7.42 & 36.34 & & \\
\hline $\begin{array}{c}\text { Socioeconomic } \\
\text { Domain at Follow- } \\
\text { up }\end{array}$ & Intervention & 35 & 66.71 & 7.35 & 47.09 & 207.000 & -5.016 & $0.0001^{\text {*** }}$ \\
\cline { 2 - 8 } & Control & 35 & 54.57 & 8.74 & 23.91 & & \\
\hline
\end{tabular}


role in this domain even though there is less difference compared to other domains of the quality of life.

Mean score of social-relationship domain were compared before and after intervention by MannWhitney $U$ test and the difference between the groups showed that there was very highly statistical significance and clinical significance in the intervention. $(p<0.0001)$. The Environmental health domain involves financial resources, security, home environment, opportunities for acquiring new information and transport. This domain had 8 questions related to above mentioned terms. Environmental factors have a great impact on the disease condition of the patient. Such as financial support which is most necessary for each individuals to lead the life. Similar to home environment and relationships with family members. And also how much safe do they feel in their life. This environmental factor indirectly supports mental illness and varies the quality of life of an individual. So it is very important to maintain a good environment around the COPD patient to manage the disease condition and to enhance the quality of life of the patient.

In this study, the mean score of environmental health domain of participated patients at baseline have not much difference between control and intervention group (Difference is 1). And mean score of environment domain at follow-up has significant difference (Difference is 16.89). The score at follow-up is increased only after the intervention (Table 5). This indicates the positive effect of the intervention.

Mean score of environmental health domain were compared before and after intervention by MannWhitney $\mathrm{U}$ test and the difference between the groups showed that there was very highly statistical significance and clinical significance in the intervention. $(p<0.0001)$.

\section{DISCUSSION}

In past 8-10 years, there is increase in chronic respiratory diseases that influence quality of life of individuals. ${ }^{11}$ Assessing QOL may lead to enhancement of the treatment. This present study compared and assessed the impact of the health related quality of life patients with COPD undergoing pulmonary rehabilitation. Result of this study shown that chronic disease affects quality of life and alter COPD management. Overall quality of life of the subjects was improved in the intervention group compared to baseline. Recruited subjects obtained highest score in physical health domain and less in social-relationship domain and medication adherence was improved.

Quality of Life of the patients with COPD undergoing pulmonary rehabilitation was assessed and it was observed that with the help of pharmacist in the form of patient education, counseling, physiotherapy and diet education there was significant increase in the scores of domains of the quality of life of the patients in interventional group $(p<0.0001)$. Physical health domain's mean score was found to be $64.86 \pm 12.72$.

In the study conducted by Beata Jankowska-Polańska et al. mean score of physical health domain was found 46.7 $(p<0.001) .{ }^{12}$ It is similar with the mean score of other domains of quality of life such as psychological health domain 60.7, Social domain 68.8 and environmental $60.3(p<0.001) .^{3}$ In present study mean score of other domains was found more compared to previous studies. Psychological domain was 63.65 , social domain 66.71 and environmental 61.17 ( $p<0.0001)$.

The median QOL score of chronic bronchitis and emphysema patients studied by Carreiro-Martins et al. was found 54, 60, 71 and 56 with respective WHOQOL domains which is less compared to present study. ${ }^{13}$ The scores obtained by present study was $64,61,69$ and 60 with respective domains $(p<0.0001)$.

The mean QOL score of chronic respiratory disease patients studied by Samiee Siboni et al. was found very less $10.32 \pm 2.83,11.27 \pm 2.69,10.51 \pm 3.83,10.25 \pm 3.28$ with respective all the domains $(\phi<0.006) .{ }^{14}$ So, it is concluded that more pharmaceutical care is required for the COPD patients to improve the quality of life.

Through this research study, it was identified that there is a need of a constant surveillance system to be incorporated into the health ${ }^{-}$care system for monitoring

\begin{tabular}{|c|c|c|c|c|c|c|c|c|}
\hline Variable & Group & $\mathbf{N}$ & Mean & SD & $\begin{array}{l}\text { Mean } \\
\text { Rank }\end{array}$ & U-Value & Z-Value & $P$-Value \\
\hline \multirow{2}{*}{$\begin{array}{c}\text { Environmental } \\
\text { Domain at Baseline }\end{array}$} & Intervention & 35 & 43.91 & 6.18 & 37.29 & \multirow[t]{2}{*}{550.000} & \multirow[t]{2}{*}{-.780} & \multirow[t]{2}{*}{0.436} \\
\hline & Control & 35 & 42.91 & 5.50 & 33.71 & & & \\
\hline \multirow{2}{*}{$\begin{array}{c}\text { Environmental } \\
\text { Domain at Follow- } \\
\text { up }\end{array}$} & Intervention & 35 & 61.17 & 9.35 & 51.01 & \multirow[t]{2}{*}{69.500} & \multirow[t]{2}{*}{-6.488} & \multirow[t]{2}{*}{$0.0001^{\text {** }}$} \\
\hline & Control & 35 & 44.28 & 5.37 & 19.99 & & & \\
\hline
\end{tabular}


the COPD patients within the tertiary care hospital to enhance the quality of life of the patients undergoing pulmonary rehabilitation. Pharmacists can help in the overall treatment of COPD by providing information to the prescriber, administrator and the patient regarding medication counseling, importance of quality of life, mental health, physical health and environmental health status. ${ }^{15}$

\section{CONCLUSION}

Through this study, it is understood that there is necessary and important role of Pharmacists in the treatment of COPD who are undergoing pulmonary rehabilitation. It is necessary to surveillance constantly the COPD patients in all the stages to reduce exacerbation and improve disease condition of the patient. After intervention, positive outcomes of the study were found. This study elaborated that clinical pharmacist's approach towards COPD patients undergoing pulmonary rehabilitation improved the disease management and quality of life of the subjects when compared to only standard treatment of the COPD.

\section{ACKNOWLEDGEMENT}

We would like to thank MD, KLE's Dr. Prabhakar Kore Hospital and MRC, Belagavi, Superintendent, KLE's Dr. Prabhakar Kore Charitable Hospital, Belagavi, Principal, KLE College of Pharmacy, Belagavi and Head of the General Medicine and Respiratory Medicine Department, KLE's Dr. Prabhakar Kore Hospital and MRC, Belagavi for providing necessary support to conduct this study.

\section{CONFLICT OF INTEREST}

The authors declare no conflict of interest.

\section{ABBREVIATIONS}

COPD: Chronic Obstructive Pulmonary Disease; GOLD: Global Initiative for Chronic Obstructive Lung Disease; QOL: Quality of Life; WHOQOL: World Health Organization Quality of Life; ADR: Adverse
Drug Reaction; SD: Standard Deviation; HIV: Human Immunodeficiency Virus.

\section{REFERENCES}

1. https://goldcopd.org/wp-content/uploads/2020/03/GOLD-2020-POCKETGUIDE-ver1.0_FINAL-WMV.pdf

2. Chen YJ, Fan JY, Guo SE, Hwang SL, Yang TM. Factors facilitating and hindering the intention to promote pulmonary rehabilitation for patients with COPD among respiratory therapists. International Journal of Chronic Obstructive Pulmonary Disease. 2017;12:2695-702.

3. Jankowska-Polańska B, Kasprzyk M, Chudiak A, Uchmanowicz I. Relation between illness acceptance and quality of life in patients with chronic obstructive pulmonary disease (COPD). Pneumonologia i Alergologia Polska. 2016;84(1):3-10.

4. Carreiro-Martins P, Gomes-Belo J, Papoila AL, Caires I, Palmeiro T, GasparMarques $\mathrm{J}$, et al. Chronic respiratory diseases and quality of life in elderly nursing home residents. Chronic Respiratory Disease. 2016;13(3):211-9.

5. Suhaj A, Manu MK, Unnikrishnan MK, Vijayanarayana K, Rao CM. Effectiveness of clinical pharmacist intervention on health-related quality of life in chronic obstructive pulmonary disorder patients: A randomized controlled study. Journal of Clinical Pharmacy and Therapeutics. 2016;41(1):78-83.

6. Verma A, Harrison A, Torun P, Vestbo J, Edwards R, Thornton J. Are pharmacists reducing COPD'S impact through smoking cessation and assessing inhaled steroid use?. Respiratory Medicine. 2012;106(2):230-4.

7. Li Q, Qu HJ, Lv D, Yeh MK, Sun S, Li L, et al. Drug-related problems among hospitalized patients with COPD in mainland China. International Journal of Clinical Pharmacy. 2019;41(6):1507-15.

8. Davis E, Marra C, Gamble JM, Farrell J, Lockyer J, Fitzgerald JM, et al. Effectiveness of a pharmacist-driven intervention in COPD (EPIC): Study protocol for a randomized controlled trial. Trials. 2016;17(1):502.

9. Ottenbros S, Teichert M, Groot RD, Griens F, Sodihardjo F, Wensing M, et al. Pharmacist-led intervention study to improve drug therapy in asthma and COPD patients. International Journal of Clinical Pharmacy. 2013;36(2):33644.

10. Gentene AJ, Guido MR, Woolf B, et al. Multidisciplinary Team Utilizing Pharmacists in Multimodal, Bundled Care Reduce Chronic Obstructive Pulmonary Disease Hospital Readmission Rates. J Pharm Pract. 2019;897190019889440. [published online ahead of print, 2019 Nov 26] doi:10.1177/0897190019889440.

11. Marx G, Nasse M, Stanze H, Boakye SO, Nauck F, Schneider N. Meaning of living with severe chronic obstructive lung disease: A qualitative study. BMJ Open. 2016;6(12):6e011555. Doi:10.1136/bmjopen-2016-011555.

12. Marshall M, Mountford J, Gamet K, et al. Understanding quality improvement at scale in general practice: A qualitative evaluation of a COPD improvement programme. $\mathrm{Br} J$ Gen Pract. 2014;64(629):e745-51. doi:10.3399/ bjgp14X682801.

13. Tommelein E, Mehuys E, Hees TV, Adriaens E, Bortel LV, Christiaens T, et al. Effectiveness of pharmaceutical care for patients with chronic obstructive pulmonary disease (PHARMACOP): A randomized controlled trial. British Journal of Clinical Pharmacology. 2014;77(5):756-66.

14. Alimoradi Z, Siboni F, Atashi V, Alipour M, Khatooni M. Quality of life in different chronic diseases and its related factors. International Journal of Preventive Medicine. 2019;10(1):65.

15. Chand S, Shastry CS, Vinay BC, Bhandari R, Kumar SS, Rawal KB. Brown, White and Blue Bagging in Special Pharmacy: An Emerging Trend to Minimize Medication Error. Journal of Global Pharma Technology. 2019;11(8):01-4. 


\section{PICTORIAL ABSTRACT}

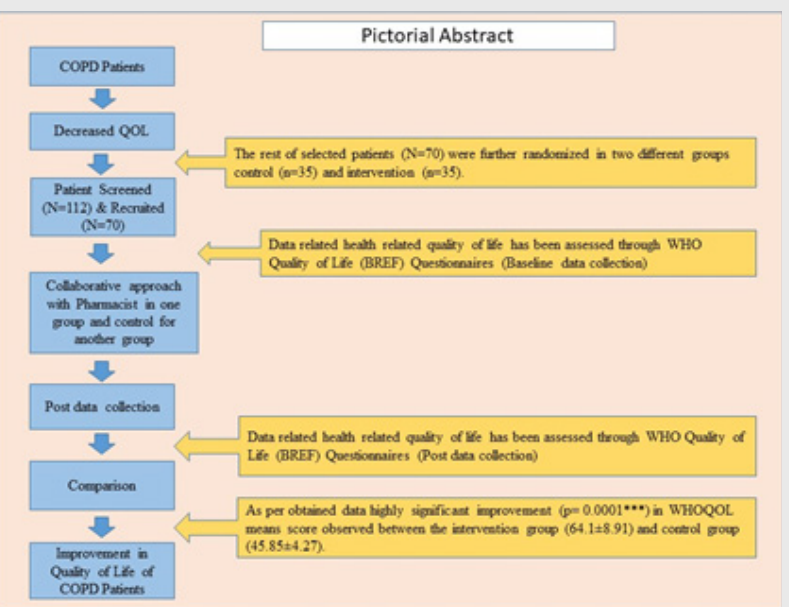

\section{SUMMARY}

Health related Quality of Life among COPD patients is not up to the standard, especially while treating with individual treatment, like pulmonary rehabilitation where most people encountered low standard of living and illiterate to treatment recommendations and decreased health related quality of life. Therefore becomes a most necessary for generating ideas with pharmacist approach and plans to improve health related quality of life in order to reduce both duration of treatment and economic burden on the patients.

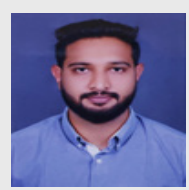

Mr. Mahantha V, Department of Pharmacy Practice, KLE College of Pharmacy, KLE Academy for Higher Education and Research (KAHER), Belagavi, Karnataka, INDIA.

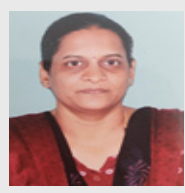

Mrs. Shashikala W, Department of Pharmacy Practice, KLE College of Pharmacy, KLE Academy for Higher Education and Research (KAHER), Belagavi, Karnataka, INDIA.
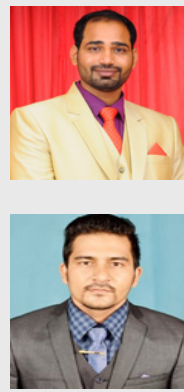

Ashish Singh Parihar, Department of Pharmacy Practice, KLE College of Pharmacy, KLE Academy for Higher Education and Research (KAHER), Belagavi, Karnataka, INDIA.

Dr. Ramesh Bhandari, Department of Pharmacy Practice, KLE College of Pharmacy, KLE Academy for Higher Education and Research (KAHER), Belagavi, Karnataka, INDIA.

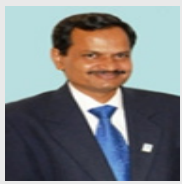

Dr. MS Ganachari, Department of Pharmacy Practice, KLE College of Pharmacy, KLE Academy for Higher Education and Research (KAHER), Belagavi, Karnataka, INDIA.

Cite this article: Mahantha V, Shashikala W, Ganachari MS, Ashish P, Bhandari R. Clinical Pharmacist Approach towards Effectiveness of Pulmonary Rehabilitation of the Patient with COPD: A Randomized Controlled Study. Indian J of Pharmaceutical Education and Research. 2021;55(1s):s318-s324. 